Article

\title{
Cognitive Dissonance in Sustainability Scientists Regarding Air Travel for Academic Purposes: A Qualitative Study
}

\author{
Isabel Schrems and Paul Upham *(i) \\ Faculty of Sustainability, Leuphana University of Lüneburg, 21335 Lüneburg, Germany; isabel.schrems@web.de \\ * Correspondence: paul.upham@leuphana.de
}

Received: 6 January 2020; Accepted: 27 February 2020; Published: 29 February 2020

\begin{abstract}
The purpose of this study is to investigate in depth the perspectives of sustainability scientists regarding academic air travel, with an emphasis on cognitive dissonance and associated coping and rationalisation strategies. The research design is case study-based, focusing on a sustainability-focused academic unit in Germany. Thematic content analysis was applied to the transcripts of 11 interviews with sustainability scientists. Analytic codes were informed by prior previously identified cognitive dissonance reduction strategies. The research design is interpretative rather than seeking representativeness. Most of the academics questioned experience some degree of cognitive dissonance relating to the disjunction between their sustainability knowledge, attitudes and flight behaviour. While this dissonance relates-as expected-to the inconsistency between pro-environmental attitudes and flying, it also relates to the contradiction of social norms that support academic flying. To resolve feelings of dissonance, the interviewees report behavioural change, suppress inconsistencies and use various justifications that include denial of control, denial of responsibility, comparisons and compensation through benefits.
\end{abstract}

Keywords: flying; academic; sustainability; scientists; cognitive dissonance

\section{Introduction}

While civil aviation is responsible for only some $2 \%$ of anthropogenic carbon dioxide $\left(\mathrm{CO}_{2}\right)$ emissions, in addition to $\mathrm{CO}_{2}$, other greenhouse gases such as nitrogen oxide $\left(\mathrm{NO}_{\mathrm{x}}\right)$, aerosols and water vapour $\left(\mathrm{H}_{2} \mathrm{O}\right)$, are emitted at high altitude, increasing radiative forcing [1]. While all forms of fossil fuel combustion for transport and other purposes have negative environmental effects, aviation has attracted critical attention in part due to the assumption that it is discretionary rather than essential一a view that is, of course, debatable. Nonetheless, technological solutions for aviation radiative forcing have been slow in coming [2] and on-going efficiency gains are unlikely to compensate for the ongoing growth of air-travel consumption [3]. In the context of increasingly stringent climate targets, fossil-fuelled aviation emissions may soon consume the major part of national emission budgets [3]. Given the resistance of the aviation sector to meaningful climate-related policy constraints [4], the onus has fallen on individuals to change their behavior. Yet voluntary renunciations in relation to air travel are not easy to achieve, even among those who are environmentally aware [5].

Awareness of the adverse effects of flying does not necessarily lead to flight renunciation [6,7]. Even those who identify themselves as environmentally conscious still choose to fly [8-10] or in some way experience pressures to fly. Given this, it would not be surprising to find that academics working on climate change and sustainability topics, who professionally seek to increase related knowledge on, and understanding and awareness of their topic, may to some extent experience an attitude-behavior gap in relation to their air-travel behavior [11].Yet there is little work probing the social psychological 
processes involved in such groups. Moreover, as social role models, their behavior may influence others' intentions to change their own behavior [11,12]. Finally, in terms of the rationale of the study, although there is research concerning the institutional factors that hinder reductions in academic air travel [11,13-17], research concerning individual-level processes relating to flight reduction is scant $[9,18]$.

A variety of individual-level theories are available for helping to explain attitude-behavior gaps. Here we use the theory of cognitive dissonance, as it is arguably the most specifically applicable approach for understanding dissonance per se. It might also be noted that the lesser-known theory of cognitive polyphasia $[19,20]$ proposes that people move between different ways of knowing or rationalities in different social contexts and thus avoid dissonance in this way. This approach arguably also merits further investigation in the context of discretionary flying, but here we focus on the application of cognitive dissonance theory [21].

According to the latter, inconsistency between cognitive elements (e.g., between cognitions about attitude and cognitions about behavior) causes aversive feelings in people, characterized by tension and discomfort. In order to reduce these negative feelings, behavior changes are one option, besides attitude changes and further resolution strategies [21-23]. Various studies have found that people rather tend to justify their flying behavior or deny its impact, instead of changing their behavior e.g., $[2,5-7,9,24-26]$. However, few studies of air travel have explicitly based their investigation on the framework of cognitive dissonance $[8,10]$ and none (to our knowledge) have researched sustainability scientists from this perspective.

This study aims to close this research gap and examines whether a small group of sustainability scientists experience an attitude-behavior gap regarding their air travel behavior in an academic context; whether they experience feelings of dissonance if they continue to fly; and how they resolve such feelings, if they exist. The study also investigates an allied line of research: McDonald et al. [10] found that people can also experience feelings of dissonance that relate to a positive social norm of flying. That is, dissonance reflecting the normalization of flying and that may hinder people from flying less. As this may well be relevant in an academic context, the study pays particular attention to the possibility of dissonance arising from socio-professional norms.

The next section provides a theoretical overview of how feelings of dissonance are aroused, how different types of dissonance have been classified in the literature and similarly what types of dissonance reduction strategy are available. The methodology section describes the method of data collection (i.e., problem-centered interviews) and the mode of data analysis. Subsequently, key findings are presented and discussed. The discussion section includes comments on the limitations of the study and implications for future research. The study concludes with a summary of the key findings and their further relevance.

\section{Theoretical Frameworks}

To analyze and understand the origins of dissonance in this context, the study draws particularly on the self-standards model of cognitive dissonance of Stone and Cooper [27], as well as on findings by McDonald et al. [10]. Whereas the main focus is on forms of dissonance directly aroused by potential and actual inconsistencies between attitudes and behavior, the study also aims to identify the origins of such dissonance, with a view to understanding what might hinder individual behavior change. The dissonance resolution strategies are informed primarily by the work of Juvan and Dolnicar [8] and also McDonald et al. [10].

\subsection{Origins of Dissonance}

The self-standards model of cognitive dissonance by Stone and Cooper [27] proposes a synthesis of several concepts and approaches to the role of the self in dissonance processes: (i) self-consistency [28,29]; (ii) self-affirmation [30]; and (iii) the New Look perspective of Cooper and Fazio [31]. According to self-consistency theory and the self-affirmation theory, people experience 
feelings of discomfort if they perceive inconsistencies between their actual behavior and personal standards or self-expectations [28,30]. In contrast, Cooper and Fazio [31] suggest that cognitions about the self are irrelevant to dissonance arousal. Instead, violations of societal or normative standards of behavior underpin cognitive dissonance. Stone and Cooper [27] propose that these distinct approaches are complementary: that idiographic dissonance is aroused if the behavior contradicts one's own behavioral expectations, while nomothetic dissonance is aroused if the behavior is compared to normative (societal) standards. Hence McDonald et al. [10] propose pro-environmental individuals may experience two distinct types of dissonance: the feeling of being out of line with their own green ideals if they choose to fly (idiographic dissonance); and the feeling of being out of line with the social norm of flying if they choose not to fly (nomothetic dissonance).

\subsection{Resolution Strategies}

Based on previous work referred to above, four types of justifications are identified as likely to be particularly relevant for this study: denial of control, denial of responsibility, comparisons and compensation through benefits. Though none of these justifications resolves the actual inconsistency between attitude and behavior, they are posited as helping to overcome feelings of dissonance. Regarding denial, Stoll-Kleemann et al. [32] argue that individuals justify inaction on climate change issues by highlighting distinct barriers to behavior change. This might especially be the case if the costs of such changes are perceived as high [5].

Juvan and Dolnicar [8] further differentiate denial of control from denial of responsibility. Denial of control may apply if a person states that the flying behavior is not under their control due to external circumstances [8]. This mainly include justifications related to the travel product (e.g., time, costs, convenience), but also to the travel context (e.g., attendance to specific events) [10]. Denial of responsibility is observed when a person thinks that his or her individual behavior cannot make a difference, which often includes feelings of powerlessness [8,32].

Furthermore, flying behavior can be justified through compensation by the benefits. In a tourism context, those benefits may include the economic profit of local communities at the destination $[6,8]$, social and cultural exchange [6], or personal benefits [24]. In terms of the theory of cognitive dissonance [21] this strategy can be interpreted as the addition of cognitive elements in order to reduce negative feelings of dissonance.

A third main strategy of both self-affirmation and dissonance avoidance is the comparison of one's own behavior with the behavior of others. Festinger [33] held that people generally compare themselves to others in order to define themselves. In this specific context, comparisons with less environmentally-aware persons or even whole industries can be used to feel better about one's own behavior [8]. This involves 'downwards comparison'.

Finally, at least in experimental settings, feelings of dissonance can be reduced by distraction [34] or forgetting [35]. A shift of attention away from the inconsistency can help to avoid negative feelings of dissonance, whilst forgetting about the inconsistency may help to reduce those feelings afterwards.

\section{Materials and Methods}

\subsection{Data Collection}

The empirical material was collected via 11 interviews with academics working on sustainability-related topics at a German university, between June and July 2019. None of the academics work specifically on sustainability in relation to aviation, but they are all specialists in sustainability-related topics and debates. Besides their area of professional focus, another selection criterion was the involvement in international projects and/or the participation in international conferences. As the academic requirements differ from position to position, the level of seniority might have an impact on the attitude towards flying and the actual flying behavior of the interviewees [11]. Therefore, the interviews were conducted across a range of levels of seniority (three full professors, 
two junior professors, two postdocs and $4 \mathrm{PhD}$ students). Further selection criteria were regarding gender-balance (six male, five female) and a variety in age (27 to 62 years).

Thematically, the interview guide focused on the following themes, with feelings of dissonance identified and probed when these arose: awareness of the environmental effects of air travel; attitudes towards air travel and the environment; any feelings of dissonance and resolution strategies; and any recommendations for institutional change to reduce academic flying. With the written consent of the interviewees, interviews were audio recorded and transcribed verbatim.

\subsection{Data Analysis}

Qualitative content analysis [36] was applied, including deductive and inductive elements. A first categorization of the data was based on theoretical considerations concerning the attitude-behavior gap and cognitive dissonance $[8-10,21,23,27]$ and existing studies about the specific context of sustainability scientists $[11,12,37]$. For the coding, the software program MAXQDA was used. To compare interviewee perspectives, the coded data were summarized within distinct subcategories and an overall thematic summary served as starting point for the evaluation of the following findings, which we present below with illustrative quotations. The quotations are allocated a scientist [S] number, to indicate the variety of sources, although these are anonymous.

\section{Results}

\subsection{Attitude-Behavior Gap and Feelings of Dissonance}

All of the interviewees were aware of the negative environmental effects of air travel. Almost all referred to the high carbon emissions of air traveling and its impact on climate change. The interviewees described the effects as "terrible" [S4], "awful" [S5], "catastrophic" [S7], "horrible" [S8] or "super bad" [S11]. The distribution of their views on air travel are also indicated in Figure 1.

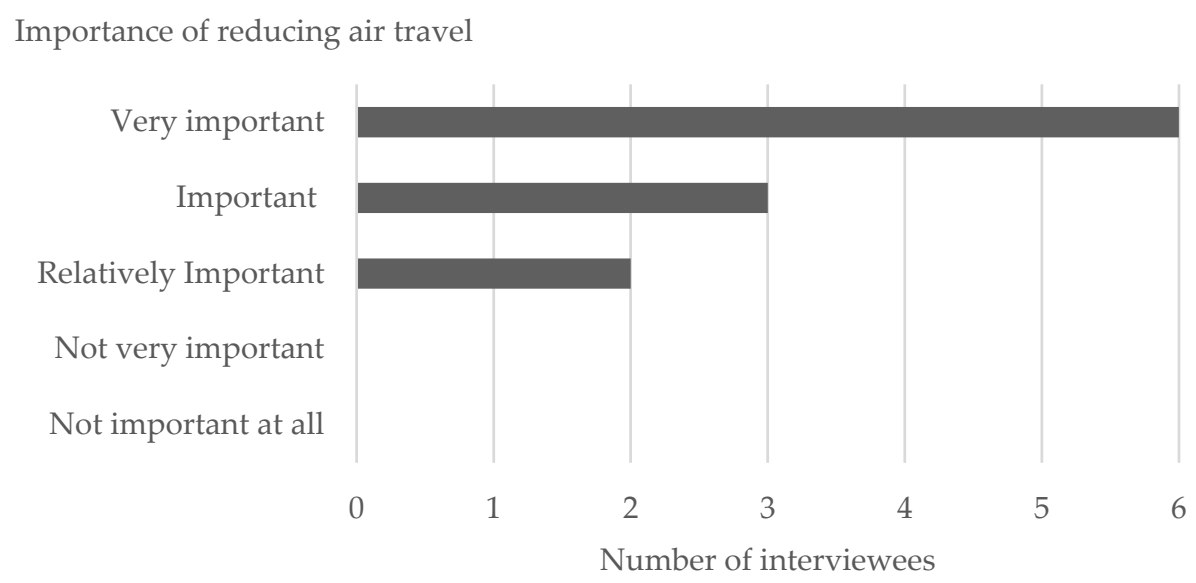

Figure 1. Perceived importance of reducing air travel: interviewee ratings on a five-point scale.

Moreover, most thought that sustainability scientists should lead by example and reduce their air travel:

And I think that increasingly our legitimacy as sustainability scientists will rightly be questioned, if we are traveling and then preaching to other people that they are being unsustainable. I think if we, who know what is happening and who know the damage of this, if we are not prepared to make individual changes, then how can we expect anyone else to? [S7].

They especially criticized flights for short meetings, networking or conferences:

There is really no excuse for us just to have thousands of people fly around the world for a conference.

That is just absurd. hmm, and we need to be showing the way on that front [S10]. 
All had used air travel for academic reasons in the last twelve months. Counting one flight every time an airplane was boarded, the interviewees reported an average (across interviewees) of 0.5 work-related flights within Germany; 2.9 flights within Europe and 5.4 flights outside Europe in the last year, averaging overall 8.8 flights per person for academic purposes. The number of flights differed at distinct career stages. On average, full professors made 12.4 flights in total, junior professors 7 flights, postdoctoral researchers 9.5 flights and PhD students 6.8 flights (Table 1). This concurs with Wynes et al. [38], who also found that that GHG emissions per individual flyer increased within the career stage.

Table 1. Flying behavior of sustainability scientists in the last 12 months: mean values split by career level and destination.

\begin{tabular}{ccccc}
\hline Flying Behavior in the Last 12 Months & PhDs & Postdocs & Junior Profs & Profs \\
\hline Flights within Germany & 0 & 1 & 2 & 0 \\
\hline Flights within Europe & 2.8 & 2 & 3 & 3.7 \\
\hline Flights outside Europe & 4 & 6.5 & 2 & 8.7 \\
\hline Flights in total & 6.8 & 9.5 & 7 & 12.4 \\
\hline
\end{tabular}

Confronted with the inconsistency between their awareness about the negative environmental effects of air travel and/or the claimed importance of reduction of air travel, almost every interviewee expressed feelings of dissonance. While few interviewees reported having a generally bad feeling or feelings of discomfort, many claimed to feel guilty or frustrated.

In addition to the variety of types of feeling, differences in intensity of feeling were also present. Some interviewees expressed very strong feelings of dissonance, while others were less emotionally involved (Table 2. Illustrative feelings of dissonance-related discomfort expressed by the interviewees Table 2).

Table 2. Illustrative feelings of dissonance-related discomfort expressed by the interviewees.

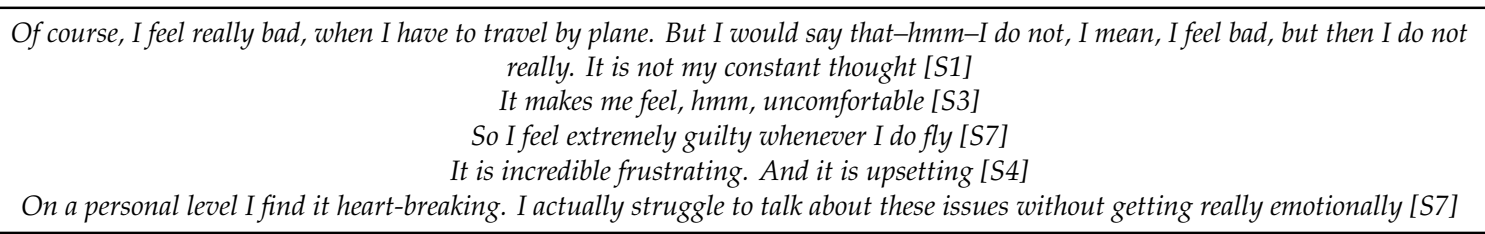

Three of the 11 interviewees explained that they do not experience those feelings [S2, S6, S8]. One said that he might feel more uncomfortable talking about these inconsistencies in a different setting, on a less intellectual level [S10].

\subsection{Origins of Dissonance}

The sustainability scientists identified various inconsistencies as origins of their feelings of dissonances, with some attributing these to idiographic types, others nomothetic types or others to both types at the same time. Many of the scientists seemed to experience types of idiographic dissonances between their pro-environmental ideals, which entail expectations towards themselves, and their contradictory behavior:

And sometimes I am little bit frustrated, because, hmm, as a sustainability scientists or someone working in the field, ehm, it is very depressing at times. Because you are constantly, constantly, hmm, having the feeling that you are not doing enough. And that you are not doing it well. And that you are harming the planet [S3]. 
Furthermore, some described an inconsistency between the norms of sustainability, which they publicly form and express, and their own behavior. Thereby, especially the expectations from others, raised by the scientists' narratives and advices, seem to play a crucial role [S5, S10].

One interviewee described an inconsistency between expectations of his colleagues and his air travel behavior, without having these expectations by himself:

Because most of them they are very engaged with sustainability in the personal level (laughs). And I am not. Not that much. hmm, so that is why I was feeling like hmm that I was not fulfilling the expectations of my colleagues. That is the thing (laughs) [S6].

On the other hand, some interviewees also stated that they experienced feelings of dissonance if they tried to reduce, or did actually reduce, the number of flights that they take, due to the normalisation of flying in an academic context:

(... ) when the organizers think that flying is okay, then I did not want to be the one/be this eco-person saying 'No, no. I am not going to take these flights, because-hmm-how dare you book flights for $m e^{\prime}[S 3]$.

\subsection{Resolution Strategies}

\subsubsection{Behavior Changes}

About half of the interviewees stated that they had reduced their flights in the past. One interviewee said that she "( . . ) made a conscious effort to stop flying" [S7]. But none of the scientists had completely quit flying in an academic context. Yet, many of them said that they reduce certain types of flights. These included flights within Europe or certain travels in the academic context, such as those to conferences or short meetings. One described very concrete efforts to reduce more than personal air travel in the research context:

So, instead of having eight researchers that need to travel there, instead we have sort of a central workshop that then trains people to go and do these different methodologies in their different places. So I think we can cut out about half of the travel requirement doing that [S7].

Some of the interviewees further emphasized their pro-environmental behavior in other consumption areas, claiming that: "it is also the overall footprint that is important" [S8]. This for example included no car use, a vegetarian diet or second-hand shopping [S8, S9, S10].

Only a few saw carbon offsetting as a meaningful option for reducing emissions. One referred to a planned compensation program with food forests for the flights of her research group [S3] and another plans to compensate step by step for all his past flights [S11].

\subsubsection{Justifications}

All of the interviewees combined the four presented types of justifications for their air travel behavior, reducing feelings of dissonance without solving the actual inconsistency. Denial of control was very prominent. Almost all named external circumstances caused by the travel product (journey time, no alternative, costs, comfort) and the travel context (expectations by university and project, career progression, research) as reasons for why they cannot stop flying. All considered journey time as a factor that made it almost impossible to not take a plane:

It is possible to travel to Stockholm by train, which I have done in the past. And I have actually run out of time from too many demands on myself, hmm, to still be able to do that [S2].

Lacking alternatives and affordable costs were also named as reasons for flying by many of the scientists, whereas comfort in total seemed to play the less important role. Some of the interviewees stressed that they find train travel to be even more comfortable than traveling by plane. Furthermore, 
almost all named expectations set by the university and their project as reasons for why they must fly. Many also thought air travel necessary for their career, including traveling to certain events, conferences or job interviews. At the beginning of their careers, in particular, attendance at certain events and networking was perceived to be very important [S1,S2,S7]. However, there were also some critical voices regarding the need for flying for career purposes:

So, I think the culture we have of short meetings at large distances away is completely superfluous. ( ... I I think the idea that we must meet as much as we do for networking and conferences and so on and to get ahead in your career and so on. I think it is simply false [S2].

Additionally, flying was often claimed to be necessary for research as many of the scientists were involved in international research projects. To them, the presence in a certain research area seemed irreplaceable for various reasons: to understand the specific regional circumstances, to maintain relationships, to create trust, to speak face-to-face, etc. Referring to these circumstances in the academic context, which were also described in previous studies $[15,16,38]$, the interviewees stressed having no other option than to fly.

Most of the interviewees considered themselves to be responsible for their behavior and behavior change per se to be highly relevant here. Nonetheless, some did deny responsibility:

(... ) and also to be clear, like I am one of seven or so billion people. Which means I have one seven billionth of responsibility to save this planet. It is not like my job to now save the world [S2].

A lot of the interviewees also stressed the necessity of deeper, systemic changes. Although this might not be understood as a concrete form of responsibility denial, it might serve to release some of the burden or discomfort of individual responsibility in the direction of institutions.

The strategy of belief in compensating for the negative impact of air travel via personal or social benefits can also be observed. The personal benefits referred to included: getting to know other places and cultures, gaining experiences and perspectives and also the adventurous and emotional aspects of traveling:

I have always loved it. hmm, I really enjoy new things. I enjoy exploring. I enjoy travel. hmm, I love seeing the world from above. I think that is really unique [S4].

Some interviewees emphasised that traveling makes them a happier person [S4, S10] and seem to see traveling as part of who they are:

(...) just being in one place all the time is actually from a life-style perspective not something I am concerned about. Because I enjoy hmm being/living in multiple places and traveling and doing that (...) $[S 10]$.

As a consequence, S9 describes colleagues, who do not travel, as scientists, who "have more or less given up".

Some of the interviewees distinguished between different travel purposes, viewing some as justifiable others not. In this regard, the length of time spent abroad played a significant role for some [S8,S11] and also the extent of the benefit gained during or via the journey [S6]. With regard to the latter, social benefits referred to included: global connectedness and exchange, increased intellectual diversity and better research results. Some of the scientists said that the results of their research might outweigh the negative effects of their personal air travels:

hmm, but I think making this contribution of helping to change the way people think about stuff has/that is the single most important challenge of our times. (...) And if that entails some flying it is probably necessary [S2]. 
Many interviewees further stressed that they try to combine different purposes (especially leisure time and work) if they fly in order to get the most out of it and make the travel 'more justified'.

Some interviewees used comparisons. They all compared the group of sustainability scientists with other socio-professional groups, such as academics from other faculties or tourists. In this way, they sought to convey that sustainability scientists fly less and worry more about their flying behavior than the others.

\subsubsection{Forgetting/Distraction}

Some of the interviewees consciously avoided thinking about the inconsistency between their pro-environmental attitude and knowledge about the negative effects of air travel and their own travel behavior. It seemed that they were very aware about the negative feelings that would arise if they confronted themselves with this inconsistency and, therefore, they actively avoided those thoughts:

I think that, if I am being honest, I do not reflect on it in a serious way. Because it would be too/I mean, you know, if I am being intellectual, you know, the kind of dissonance that it would create would make one not enjoy next time [S10].

\subsection{Recommendations for Institutional Change}

Few interviewees thought that their university facilitates individual reductions in air travel. Some had the impression that the university rather works against air travel reductions by offering global study programs, enhancing global research projects and offering financial support for travel [S6,S7]. Some thought that the only interventions that might reduce air travel are enhanced ease of videoconferencing [S2] and funders/travel authorisers requiring an explanation for why air travel is chosen [S1,S5]. Others also suggested incentives such as discounted rail travel and support for train booking. Suggestions for restrictions included strict limitations on the number of flights per faculty member per year, the prohibition of flights in Germany or Europe and the elimination of funding for particular conferences. Measures relating to increased time flexibility concerned allowing longer travel time to events and more flexibility for combining private purposes with business travel. Some called for the inclusion of compensation costs into cost calculations and the accounting of the carbon footprint of each department, faculty or written paper, combined with emission reduction goals. Others saw a general mindset shift within the academic culture as required:

So, a lot of the reasons why travel needs to be so super fast is that we are in this hype-charged super fast environment. (...) I mean it is this insanity overall that needs to change and then everything else will change. So see, I do not believe in faster alternatives. I believe in a slowing down of what we do [S2].

This mindset shift might include time aspects, but also other aspects such as the chosen research areas themselves. Table 3 summarises the interviewees' suggestions.

Table 3. Interviewees' recommendations for institutional change.

\begin{tabular}{cc}
\hline Facilitations & Support for train booking \\
Incentives & Improved teleconferencing equipment \\
Special train offers (e.g., BahnCard 25/50) & Accounting of carbon footprint of each department, faculty etc. or per written paper combined with reduction goals \\
Specific incentives (e.g., accommodation upgrade) for scientists using non-aviation transportation \\
Limitation of number of flights per faculty member per year \\
Prohibition of flights within Germany/Europe \\
Establishment of train travel as first priority within Europe \\
Reduction of conference funding per se \\
Restrictions \\
Elimination of passive conference funding (i.e., when not presenting) \\
Making it easier to combine business travel with private purposes \\
More flexibility in teaching schedules \\
More flexibility in travel time to events (e.g., time buffer for/after event) \\
Time credit, if alternative means of transport take longer \\
Support for care-taking of relatives during longer travels \\
Mindset shift \\
Embodiment of sustainability values in the academic context (e.g., enhance slower, \\
more focused behavior instead of encouraging faster alternatives) \\
Faculty level focus on work in Europe rather than worldwide \\
Self-reflection as to whether flying is necessary
\end{tabular}




\section{Discussion and Research Directions}

\subsection{Attitude-Behavior Gaps and Feelings of Dissonance}

Almost every interviewee expressed feelings of dissonance. Whereas feelings of guilt in relation to flying have been previously documented [2,8-10,18,25,39], feelings of frustration relating to the topic, which were common here, have not previously been documented. This matters not only per se, but because the specific affective state may influence the adoption of a particular mode of dissonance reduction [23]. In the context of cognitive dissonance, guilt is often identified as the major or only emotion driving dissonance reduction [23,40]. Yet the negative emotion of frustration tends to result in enhanced efforts towards taking action, relative to negative emotions such as sadness and hopelessness [41]. This issue of the variety of types of emotions, their intensity and their relationship to dissonance and dissonance-reducing action constitute a notable direction for further research.

\subsection{Origins of Dissonance}

Both ideographic and nomothetic dissonance—as characterized by McDonald et al. [10]—were present in this case. For McDonald et al. [10], the social discomfort of not flying (nomothetic dissonance) is in general more difficult to overcome than the dissonance directly aroused by the inconsistency between personal pro-environmental attitude and the own flying behavior (ideographic dissonance). Some of the interviewees seem to have reduced nomothetic dissonance by reducing rather than eliminating flying, and research in other study areas has also found that people tend to solve idiographic dissonances through action or attitude change, while avoiding nomothetic dissonances [42].

The (perhaps) more expected type of nomothetic dissonance-of being out of line with pro-environmental norms that are institutionally established or raised by others-was also evident. Moreover this indicates conflicting institutional norms at the university: on the one hand, the norm of flying is embedded in the overall academic system [15,16], enhanced by other sectors [15] and does not seem to be questioned in the sustainability policies of the university. On the other hand, the sustainability values taught and privately held by sustainability scientists create a flying-critical attitude, which can be interpreted as a social norm on a group level [43].

As nomothetic dissonance in general seems to be more difficult to overcome than idiographic dissonance and can lead to avoidance of dissonance by following the relevant social norm [10], the question that this raises is: which of the conflicting norms arouses feelings of dissonance within the scientists? While the nomothetic dissonance aroused by the norm of flying could hinder flight reductions, the other type aroused by sustainability norms could trigger them.

The scientists' self-concept may be decisive for the type of dissonance that arises. Theoretical conceptions of self-concept range from an exclusively personal identity to an exclusively social identity [44]. Self-concepts are multi-faceted and evolve through a process of self-categorization, which includes comparisons between the self and others [45]. As might be expected, people can experience greater levels of dissonance if their behavior is not supported by a social group they identify with than if no group is personally relevant [46]. This in turn suggests it would be the social group that the sustainability scientist identifies him- or herself with, and to what extent that would determine or strongly influence the type of nomothetic dissonance that they experienced. Again, these influences would need probing empirically here and in other contexts.

\subsection{Resolution Strategies}

Of the previously identified types of justifications, denial of control, denial of responsibility and compensation through benefits were found to be the most prominent types in this case. Consistent with their scientific knowledge and roles, the sustainability scientists did not deny climate change, nor the consequences of individual flying behavior-unlike some previously-studied groups $[8,26]$. Yet that sustainability scientists use forgetting or distraction (perhaps more accurately described in this case as neglect) as a resolution mechanism is surprising, given that they are dealing with the 
topic of sustainability continuously. Other relevant studies in the context of air travel have rarely observed this strategy being deployed for dissonance reduction, an exception being Higham et al. [7]. For some individuals, this may well involve a conscious process of thought suppression rather than an unconscious process of repression, given that some of the scientists seemed to be actively motivated to forget about the inconsistency between their attitude and their behavior [47].

In general, the observed types of denial of responsibility and denial of control concerning air travel were similar to previous findings relating to private and business contexts [8-11,48]. However, while air travel for personal reasons is justified by individuals as reflecting e.g., the desire to get away [7] or visiting friends and family [2,10], here academic air travel, as business air travel, is justified by the scientists as a necessity. Yet that necessity is to some extent socially constructed. The narrative that air travel is necessary for the academic career or that sustainability scientists need to play roles in the international field or undertake international collaborative research, can be found in various studies [49-51]. Yet the empirical relationship between air travel and citations can be weak [38]. Some of the scientists interviewed here concurred that a high level of air travel is not necessary for the core scientific task of producing and disseminating research: they had stopped attending some events and had developed alternative models of international collaboration that entail less traveling. Others took a different view. As a possible explanation for the latter, Cherrier et al. [52] propose that needs are embedded in social relationships, which makes them difficult to re-evaluate on an individual level. Therefore, scientists might not be able to differentiate the 'true' necessity of air traveling from the 'false' one [52]. The denial strategies that scientists use to resolve feelings of dissonance could also strengthen the perceived necessity and create discursive barriers of individual behavior changes [26].

Furthermore, referring to the benefits of air travel can also be expected to strengthen the norm of flying, as it may lead to a 'spreading of alternatives'. This means that the chosen behavior is viewed more positively, while alternatives seem less attractive [53]. According to Bastian and Loughnan [54], the defense of one's own behavior recruits others to behave in the same way and to share this point of view more widely, impacting society on a broader level.

Arguably, to reduce the possibility that individual justifications mechanisms further strengthen socially constructed norms, there needs to be critical reflection on the reasons why academics continue to fly heavily. The necessity of air travel in the academic context, as well as its benefits, need to be questioned not only on a personal level, but also on an institutional level. Storme et al. [49] suggest that a minimum amount of travel is necessary for academics in order to be successful, which might be the case especially in the early stages of a career. More research is necessary to define this minimum. It might also be noted that the latter may be part of wider forms of institutionalized incentives for air travel, such as those relating to researcher mobility funded by the European Union. Moreover, personal and professional motives for travel can become blurred when researchers form personal relationships with people in distant locations, leading to lock-in of long-distance travel.

\section{Conclusions}

This study is intended to contribute to the understanding of a case of attitude-behavior gap in the context of academic air travel, by examining the personal perspectives of sustainability scientists at an exemplar university. The scientists are shown to face an attitude-behavior gap similar to that found in previously-studied traveler groups. They are aware of the negative environmental effects of air traveling and believe that scientists in this field of research should lead by example and reduce their air travel. Yet the scientists continue to average several professional flights per year.

- The theory of cognitive dissonance helps to explain the responses of the sustainability scientists questioned. Confronted with the inconsistency between their attitude towards flying and their personal flying behavior, the interviewees did indeed express feelings of dissonance. Examination of the self-identified origins of these feelings shows that they are not only aroused because the personal flying behavior contradicts a personal pro-environmental attitude. Contradiction of 
social norms for flying also leads to feelings of dissonance, and this might be even more difficult to overcome.

- $\quad$ Some of the scientists might change their flying behavior in order to reduce feelings of dissonance. However, they also suppress inconsistencies between attitude and behavior and use various justifications for their flights. These justifications include denial of control, denial of responsibility, comparisons and compensation through benefits, all of which have been previously identified as typical responses to inner conflict.

- As Hanna and Adams [26] argue, the perceived barriers to behavior change for sustainability are at least partly socially constructed. This may be viewed as the case for the perceived necessity of air travel in the academic context and its claimed benefits. In order to avoid the justification strategies further strengthening socially constructed barriers, we have advocated critical reflection on the necessity and benefits of air travel in the academic context. The scientists themselves also advocated a variety of practical support, incentives and constraints on academic air travel. While many of the drivers of academic air travel are strongly institutionalised and subject to path dependencies that make change difficult, there nonetheless remains scope for voluntary reductions in the number of academic flights taken-something that universities internationally have a duty to assist with. In addition, sustainability academics might also do well to understand better the relative scale of alternative emissions reduction options, given that these are not always obvious [55].Complicating this is the need to provide guidance whilst being aware that apparently simple emission factor averages used to compare transport modes can obscure subtle calculation decisions There is no doubt that flying has a negative climate impact due to fossil kerosene combustion. There is also a strong case for arguing that the technological response of the aviation sector has been inadequate vis-à-vis climate imperatives [4]. This notwithstanding, comparing the environmental impacts of different transport modes through the use of average emission factors can be misleading. Key issues include system boundary assumptions (what infrastructure, if any, to include, as well as what time periods-an issue that is particularly relevant in the case of new, long distance rail routes).

- Whether one conceives of the cognitive strategies that academics use to avoid or reduce inner conflict as the coping strategies of cognitive dissonance or evidence of different rationalities in different social contexts [20], the adverse climate impact of flying will remain while technological change lags behind climate imperatives, and many if not most academics are caught up in this. Regardless of the pro-flight social and professional pressures that academics may experience, they (we!) also need to consider the impact of our behaviour in terms of credibility losses [56,57].

Author Contributions: Conceptualization and methodology by I.S. and P.U.; validation, formal analysis, investigation and data curation by I.S.; writing — original draft preparation by I.S.; writing — review and editing by P.U.; supervision by P.U. All authors have read and agreed to the published version of the manuscript.

Funding: This research received no external funding.

Acknowledgments: We thank all participants for their honesty and engagement. Furthermore, we thank Maraja Riechers for her support.

Conflicts of Interest: The authors declare no conflict of interest.

\section{References}

1. International Civil Aviation Organization (ICAO). ICAO Environmental Report 2016: Aviation and Climate Change; ICAO: Montreal, QC, Canada, 2016; Available online: https://www.icao.int/environmental-protection/ Documents/ICAO\%20Environmental\%20Report\%202016.pdf (accessed on 5 January 2020).

2. Cohen, S.A.; Higham, J.; Cavaliere, C.T. Binge flying. Ann. Tour. Res. 2011, 38, 1070-1089. [CrossRef]

3. Bows, A.; Anderson, K.; Peeters, P. Air transport, climate change and tourism. Tour. Hosp. Plan. Dev. 2009, 6, 7-20. [CrossRef] 
4. Gössling, S.; Upham, P. Climate Change and Aviation: Issues, Challenges and Solutions; Earthscan Ltd.: London, UK, 2009.

5. Barr, S.; Shaw, G.; Coles, T.; Prillwitz, J. 'A holiday is a holiday': practicing sustainability, home and away. J. Transp. Geogr. 2010, 18, 474-481. [CrossRef]

6. Hares, A.; Dickinson, J.; Wilkes, K. Climate change and the air travel decisions of UK tourists. J. Trans. Geogr. 2010, 18, 466-473. [CrossRef]

7. Higham, J.; Cohen, S.A.; Cavaliere, C.T. Climate Change, Discretionary Air Travel, and the 'Flyers' Dilemma'. J. Travel Res. 2014, 53, 462-475. [CrossRef]

8. Juvan, E.; Dolnicar, S. The attitude-behaviour gap in sustainable tourism. Ann. Tour. Res. 2014, 48, 76-95. [CrossRef]

9. Lassen, C. Environmentalist in Business Class: An Analysis of Air Travel and Environmental Attitude. Transp. Rev. 2010, 30, 733-751. [CrossRef]

10. McDonald, S.; Oates, C.J.; Thyne, M.; Timmis, A.J.; Carlile, C. Flying in the face of environmental concern: why green consumers continue to fly. J. Mark. Manag. 2015, 31, 1503-1528. [CrossRef]

11. Le Quéré, C.; Capstick, S.; Corner, A.; Cutting, D.; Johnson, M.; Minns, A.; Schroeder, H.; Walker-Springett, K.; Whitmarsh, L.; Wood, R. Towards a Culture of Low-Carbon Research for the 21st Century; Working Paper No. 161; Tyndall Centre for Climate Change Research: Norwich, UK, 2015; Available online: https:/tyndall.ac.uk/sites/default/files/twp161.pdf (accessed on 5 January 2020).

12. Attari, S.Z.; Krantz, D.H.; Weber, E.U. Statements about climate researchers' carbon footprints affect their credibility and the impact of their advice. Clim. Chang. 2016, 138, 325-338. [CrossRef]

13. Caset, F.; Boussauw, K.; Storme, T. Meet \& fly: Sustainable transport academics and the elephant in the room. J. Transp. Geogr. 2018, 70, 64-67. [CrossRef]

14. Fraser, H.; Soanes, K.; Jones, S.A.; Jones, C.S.; Malishev, M. The Value of Virtual Conferencing for Ecology and Conservation: Virtual Conferencing. Conserv. Biol. 2017, 31, 540-546. [CrossRef] [PubMed]

15. Glover, A.; Strengers, Y.; Lewis, T. The unsustainability of academic aeromobility in Australian universities. Sustain. Sci. Pract. Policy 2017, 13, 1-12. [CrossRef]

16. Hopkins, D.; Higham, J.; Tapp, S.; Duncan, T. Academic mobility in the Anthropocene era: A comparative study of university policy at three New Zealand institutions. J. Sustain. Tour. 2016, 24, 376-397. [CrossRef]

17. Stroud, J.T.; Feeley, K.J. Responsible academia: optimizing conference locations to minimize greenhouse gas emissions. Ecography 2015, 38, 402-404. [CrossRef]

18. Nursey-Bray, M.; Palmer, R.; Meyer-Mclean, B.; Wanner, T.; Birzer, C. The Fear of Not Flying: Achieving Sustainable Academic Plane Travel in Higher Education Based on Insights from South Australia. Sustainability 2019, 11, 2694. [CrossRef]

19. Moscovici, S. La Psychanalyse, Son Image et Son Public: étude sur la Réprésentation Sociale de la Psychanalyse; Presses Universitaires de France: Paris, France, 1961.

20. Jovchelovitch, S.; Priego-Hernández, J. Cognitive polyphasia, knowledge encounters and public spheres. In The Cambridge Handbook of Social Representations; Gordon, S., Andreouli, E., Gaskell, G., Valsiner, J., Eds.; Cambridge University Press: Cambridge, UK, 2015; pp. 163-178.

21. Festinger, L. A Theory of Cognitive Dissonance, 2nd ed.; Stanford University Press: Stanford, CA, USA, 1957.

22. Gawronski, B.; Peters, K.R.; Strack, F. Cross-Cultural Differences Versus Universality in Cognitive Dissonance: A Conceptual Reanalysis. In Handbook of Motivation and Cognition Across Cultures; Sorrentino, R.M., Yamaguchi, S., Eds.; Elsevier: New York, NY, USA, 2008; pp. 297-314.

23. McGrath, A. Dealing with dissonance: A review of cognitive dissonance reduction. Soc. Personal. Psychol. Compass 2017, 11, e12362. [CrossRef]

24. Becken, S. Tourists' Perception of International Air Travel's Impact on the Global Climate and Potential Climate Change Policies. J. Sustain. Tour. 2007, 15, 351-368. [CrossRef]

25. Cohen, S.A.; Higham, J.; Reis, A.C. Sociological barriers to developing sustainable discretionary air travel behaviour. J. Sustain. Tour. 2013, 21, 982-998. [CrossRef]

26. Hanna, P.; Adams, M. Positive self-representations, sustainability and socially organised denial in UK tourists: discursive barriers to a sustainable transport future. J. Sustain. Tour. 2019, 27, 189-206. [CrossRef]

27. Stone, J.; Cooper, J. A Self-Standards Model of Cognitive Dissonance. J. Exp. Soc. Psychol. 2001, 37, $228-243$. [CrossRef] 
28. Aronson, E. The Theory of Cognitive Dissonance: A Current Perspective. In Advances in Experimental Social Psychology; Academic Press: Cambridge, MA, USA, 1969; Volume 4, pp. 1-34. [CrossRef]

29. Thibodeau, R.; Aronson, E. Taking a closer look: Reasserting the role of the self-concept in dissonance theory. Personal. Soc. Psychol. Bull. 1992, 18, 591-602. [CrossRef]

30. Steele, C.M. The psychology of self-affirmation: Sustaining the integrity of the self. In Advances in Experimental Social Psychology; Berkowitz, L., Ed.; Academic Press: San Diego, CA, USA, 1988; pp. 261-302.

31. Cooper, J.; Fazio, R.H. A new look at dissonance theory. Adv. Exp. Soc. Psychol. 1984, 17, 229-266. [CrossRef]

32. Stoll-Kleemann, S.; O'Riordan, T.; Jaeger, C.C. The psychology of denial concerning climate mitigation measures: evidence from Swiss focus groups. Global Environ. Chang. 2001, 11, 107-117. [CrossRef]

33. Festinger, L. A theory of social comparison processes. Human Relat. 1954, 7, 117-140. [CrossRef]

34. Zanna, M.P.; Aziza, C. On the interaction of repression-sensitization and attention in resolving cognitive dissonance. J. Personal. 1976, 44, 577-593. [CrossRef] [PubMed]

35. Elkin, R.A.; Leippe, M.R. Physiological arousal, dissonance, and attitude change: evidence for a dissonance-arousal link and a 'don't remember me' effect. J. Personal. Soc. Psychol. 1986, 51, 55-65. [CrossRef]

36. Kuckartz, U. Qualitative Inhaltsanalyse, Methoden, Praxis Computerunterstützung, 2nd ed.; Beltz Juventa: Weinheim, Germany, 2014.

37. Fox, H.E.; Kareiva, P.; Silliman, B.; Hitt, J.; Lytle, D.A.; Halpern, B.S.; Hawkes, C.V.; Lawler, J.; Neel, M.; Olden, J.D.; et al. Why do we fly? Ecologists' sins of emission. Front. Ecol. Envir. 2009, 7, 294-296. [CrossRef]

38. Wynes, S.; Donner, S.D.; Tannason, S.; Nabors, N. Academic air travel has a limited influence on professional success. J. Clean. Prod. 2019, 226, 959-967. [CrossRef]

39. Higham, J.; Reis, A.; Cohen, S.A. Australian climate concern and the 'attitude-behaviour gap'. Curr. Issues Tour. 2016, 19, 338-354. [CrossRef]

40. Kenworthy, J.B.; Miller, N.; Collins, B.E.; Read, S.J.; Earleywine, M. A trans-paradigm theoretical synthesis of cognitive dissonance theory: Illuminating the nature of discomfort. Eur. Rev. Soc. Psychol. 2011, 22, 36-113. [CrossRef]

41. Carver, C.S.; Scheier, M.F. Feedback processes in the simultaneous regulation of action and affect. In Handbook of Motivation Science; Shah, J.Y., Gardner, W.L., Eds.; Guilford Press: New York, NY, USA, 2008; pp. 308-324.

42. Balestrino, A.; Ciardi, C. Social Norms, cognitive dissonance and the timing of marriage. J. Socio-Econ. 2008, 37, 2399-2410. [CrossRef]

43. Hogg, M.A.; Reid, S.A. Social identity, self-categorization, and communication of group norms. Commun. Theor. 2006, 16, 7-30. [CrossRef]

44. Hogg, M.A.; Abrams, D. Social Identifications; Routledge: London, UK, 1988.

45. Hibbert, J.F.; Dickinson, J.E.; Gössling, S.; Curtin, S. Identity and tourism mobility: an exploration of the attitude-behaviour gap. J. Sustain. Tour. 2013, 21, 999-1016. [CrossRef]

46. McKimmie, B.M.; Terry, D.J.; Hogg, M.A.; Manstead, A.S.; Spears, R.; Doosje, B. I'm a hypocrite, but so is everyone else: Group support and the reduction of cognitive dissonance. Group Dyn. Theor. Res. Pract. 2003, 7, 214-224. [CrossRef]

47. Boag, S. Repression, suppression, and conscious awareness. Psychoanal. Psychol. 2010, 27, 164-181. [CrossRef]

48. Randles, S.; Mander, S. Practice(s) and ratchet(s): A sociological examination of frequent flying. In Climate Change and Aviation: Issues, Challenges and Solutions; Gössling, S., Upham, P., Eds.; Earthscan: London, UK, 2009; pp. 245-271.

49. Storme, T.; Beaverstock, J.V.; Derrudder, B.; Faulconbridge, J.R.; Witlox, F. How to cope with mobility expectations in academia: Individual travel strategies of tenured academics at Ghent University, Flanders. Res. Transp. Bus. Manag. 2013, 9, 12-20. [CrossRef]

50. Storme, T.; Faulconbridge, J.R.; Beaverstock, J.V.; Derudder, B.; Witlox, F. Mobility and Professional Networks in Academia: An Exploration of the Obligations of Presence. Mobilities 2017, 12, 405-424. [CrossRef]

51. Higham, J.E.S.; Hopkins, D.; Orchiston, C. The work-sociology of academic aeromobility at remote institutions. Mobilities 2019, 14, 1-20. [CrossRef]

52. Cherrier, H.; Szuba, M.; Özçağlar-Toulouse, N. Barriers to downward carbon emission: Exploring sustainable consumption in the face of the glass floor. J. Mark. Manag. 2012, 28, 397-419. [CrossRef]

53. Harmon-Jones, E.; Harmon-Jones, C. Testing the action-based model of cognitive dissonance: The effect of action orientation on postdecisional attitudes. Personal. Soc. Psychol. Bull. 2002, 28, 711-723. [CrossRef] 
54. Bastian, B.; Loughnan, S. Resolving the Meat-Paradox: A Motivational Account of Morally Troublesome Behavior and Its Maintenance. Personal. Soc. Psychol. Rev. 2017, 21, 278-299. [CrossRef] [PubMed]

55. Mackay, D. Sustainable Energy_Without the Hot Air; UIT Cambridge: Cambridge, UK, 2008; Available online: https://www.withouthotair.com/download.html (accessed on 3 February 2020).

56. Attari, S.Z.; Krantz, D.H.; Weber, E.U. Climate change communicators' carbon footprints affect their audience's policy support. Clim. Change 2019, 154, 529-545. [CrossRef]

57. Sparkman, G.; Attari, S.Z. Credibility, communication, and climate change: How lifestyle inconsistency and do-gooder derogation impact decarbonization advocacy. Energy Res. Soc. Sci. 2020, 59, 101290. [CrossRef]

(C) 2020 by the authors. Licensee MDPI, Basel, Switzerland. This article is an open access article distributed under the terms and conditions of the Creative Commons Attribution (CC BY) license (http://creativecommons.org/licenses/by/4.0/). 